\title{
Consumo, digestibilidade e estimativa do valor energético de alguns volumosos por meio da composição química ${ }^{1}$
}

\author{
Patrícia Regina de Souza Siqueira Campos², Sebastião de Campos Valadares Filho ${ }^{3}$,Edenio Detmann ${ }^{3}$, \\ Paulo Roberto Cecon', Maria Ignez Leão ${ }^{5}$,Bruno Barcelos Lucchi ${ }^{6}$, Shirley Motta de Souza7, Odilon Gomes Pereira ${ }^{3}$
}

\section{RESUMO}

Avaliou-se o consumo, a digestibilidade dos nutrientes e o teor de nutrientes digestíveis totais (NDT) da cana-deaçúcar e das silagens de capim-elefante, de milho e de sorgo em ovinos. Além disso, estimou-se o teor de NDT de acordo com o sistema de equações proposto pelo NRC (2001). Foram utilizados 20 ovinos, sem raça definida, machos, castrados, alojados em gaiolas de metabolismo, distribuídos em um delineamento inteiramente casualizado, sendo quatro tratamentos (volumosos) e cinco repetições (animais). A determinação da digestibilidade dos nutrientes foi realizada pela coleta total de fezes, com uso de sacolas coletoras. A comparação dos valores de NDT observados e estimados foi feita por meio do ajuste do modelo de regressão linear simples dos valores preditos sobre os valores observados. Os ovinos alimentados com as silagens consumiram maiores quantidades $(\mathrm{P}<0,05)$ de matéria seca (MS), proteína bruta (PB), extrato etéreo (EE) e fibra em detergente neutro (FDN) em relação aos alimentados com cana-de-açúcar. Não houve diferença $(\mathrm{P}>0,05)$ para o consumo de NDT entre as silagens. As digestibilidades aparentes da MS, MO, PB e EE não diferiram $(P>0,05)$ entre os tratamentos. Constataram-se diferenças $(P<0,05)$ entre os valores estimados e observados de NDT e das frações digestíveis da PB, da FDN e dos carboidratos não-fibrosos (CNF). As equações propostas pelo NRC (2001) mostraram-se inadequadas para estimar o valor energético dos volumosos para ovinos.

Palavras-chave: Fibra em detergente neutro, nutrientes digestíveis totais, ovinos, silagem, valor nutritivo.

\begin{abstract}
Intake, digestibility and energetic value estimates of feedstuff through chemical composition

Nutrient intake, apparent digestibility and total digestible nutrients (TDN) levels of sugar cane, elephant grass silage, corn silage and sorghum silage were evaluated in sheep. The TDN values of feeds were also estimated with the equations proposed by NRC (2001). Twenty male castrated rams, housed in individual pens, were distributed in a randomized design in four treatments (feedstuffs) and five repetitions (animals). Nutrient apparent digestibility was determined by using total collection of feces. To compare predicted TDN values with in vivo TDN values, data were adjusted to a linear regression model. Sheep fed with the silages consumed larger amounts $(\mathrm{P}<0.05)$ of nutrients than those fed with sugar cane. There was not difference $(\mathrm{P}>0.05)$ for TDN intake among silages. The apparent digestibility of the dry matter (DM), organic matter (OM), crude protein (CP), ethereal extract (EE) and neutral detergent fiber (NDF) did not differ $(\mathrm{P}>0.05)$ among treatments. There was difference $(\mathrm{P}<0.05)$ between predicted and in vivo values of TDN. The equations proposed by NRC (2001) were not suitable to predict energetic value of tropical forages.
\end{abstract}

Key Words: Silage, sheep, neutral detergent fiber, nutritive value, total digestible nutrients

\footnotetext{
Recebido para publicação em agosto de 2008 e aprovado em julho de 2009 1 Parte da Dissertação de mestrado do Primeiro Autor - CNPq.

2Zootecnista, Mestre. Universidade Estadual Norte Fluminense, Avenida Alberto Lamego, 2000, 28013-602, Campos dos Goytacazes, RJ, Brasil. patriciarcampos@yahoo.com.br 3Zootecnista, Doutor. Universidade Federal de Viçosa, Departamento de Zootecnia, Av. P.H. Rolfs S/N, 36570-000, Viçosa, MG, Brasil. scvfilho@ufv.br, odilon@ufv.br e mileao@ufv.br, detmann@ufv.br

${ }^{4}$ Engenheiro-Agrônomo, Doutor. Universidade Federal de Viçosa, Departamento de Informática, Av. P.H. Rolfs S/N, 36570-000,Viçosa, MG, Brasil. cecon@dpi.ufv.br ${ }^{5}$ Médica Veterinária, Doutora. Universidade Federal de Viçosa, Departamento de Zootecnia, Av. P.H. Rolfs S/N, 36570-000, Viçosa, MG, Brasil. mileao@ufv.br ${ }^{6}$ Zootecnia. Confederação da Agricultura e Pecuária do Brasil (CNA), SGAN, Quadra 601, Lote K, 70.830-903, Brasília, DF, Brasil. bruno.lucchi@cna.org.br ${ }^{7}$ Zootecnista, Mestre. Universidade Federal de Viçosa, Departamento de Zootecnia, Av. P.H. Rolfs S/N, 36570-000, Viçosa, MG, Brasil. shirleymotta@yahoo.com.br
} 


\section{INTRODUÇÃO}

A ingestão de matéria seca é fundamentalmente importante na nutrição animal, por estabelecer a quantidade de nutrientes necessários para atendimento dos requisitos de mantença e de produção dos animais. O conhecimento da composição química dos alimentos e da sua digestibilidade é essencial para a formulação de dietas balanceadas que possibilitem maximizar a eficiência alimentar. Tendo em vista que a alimentação contribui com elevado percentual dos custos no sistema de produção de bovinos, a utilização de alimentos volumosos, de elevado valor nutritivo, na dieta de ruminantes é uma estratégia apropriada na busca por eficiência produtiva e econômica.

No Brasil, as informações sobre o valor nutritivo dos alimentos utilizados para animais são escassas, indicando a necessidade de mais pesquisas, principalmente no que diz respeito ao valor energético, uma vez que, segundo Weiss (1993), a energia é um atributo nutricional limitante no desempenho dos ruminantes, em especial para vacas de alta produção.

Segundo Capelle et al. (2001), a carência de um método rápido, barato e acurado capaz de medir a disponibilidade de energia dos alimentos para os animais é reconhecida pelos que trabalham com formulação e controle de qualidade das rações. Sendo assim, têm sido realizados vários estudos com o objetivo de encontrar um método indireto para estimar o valor energético dos alimentos.

O teor de nutrientes digestíveis totais (NDT) é um parâmetro muito utilizado para a quantificação da energia disponível dos alimentos. O NRC (2001) propôs um conjunto de equações somativas que considera cada fração do alimento para estimar o teor de nutrientes digestíveis totais (NDT) dos bovinos em mantença. Porém, tais equações carecem de validação antes de serem recomendadas para estimar o valor energético dos alimentos produzidos em condições tropicais, principalmente em relação à digestibilidade da fibra em detergente neutro (FDN).

Basicamente são três os componentes que determinam o valor energético dos alimentos utilizados nas dietas de ruminantes: extrato etéreo (devido à sua elevada densidade energética), teor de carboidratos não-fibrosos, em função de sua alta digestibilidade, e teor e digestibilidade da fração de carboidratos fibrosos, em virtude do elevado nível na composição das dietas para ruminantes. Contudo, uma acurada estimativa da digestibilidade de carboidratos fibrosos, geralmente definida como FDN, necessita ser desenvolvida (Robinson et al., 2004).

Além disso, no Brasil as equações propostas pelo NRC (2001) deverão ser validadas para se estimar o valor energético dos alimentos produzidos, principalmente dos volumosos e especialmente no que diz respeito à digestibilidade da FDN (Rocha Júnior et al., 2003b).
Baseado na importância dos alimentos volumosos para a pecuária brasileira, conduziu-se o presente trabalho, objetivando avaliar o consumo e a digestibilidade aparente total da cana-de-açúcar e das silagens de capimelefante, de milho e de sorgo, em um ensaio com ovinos, bem como estimar os teores de NDT pelo sistema de equações proposto pelo NRC (2001).

\section{MATERIAL E MÉTODOS}

O presente trabalho foi conduzido nas dependências do Laboratório Animal do Departamento de Zootecnia da Universidade Federal de Viçosa, no mês de setembro de 2003.

Foram utilizados 20 ovinos machos, adultos, castrados, sem raça definida, com peso corporal médio de $50 \mathrm{~kg}$, previamente tratados com vermífugos. Os animais foram pesados antes do período de adaptação, assim como no início e no final do período experimental. Os ovinos foram alojados em gaiolas de metabolismo individualmente, procedendose sua distribuição nos tratamentos, num delineamento inteiramente casualizado.

As dietas foram oferecidas ad libitum, e os animais tiveram livre acesso à água e ao sal mineral. Foram utilizadas quatro dietas experimentais, compostas em maior proporção pela cana-de-açúcar (Saccharum officinarum L.), silagem de capim-elefante (Pennisetum purpureum, Schum), silagem de milho (Zea mays L.) e silagem de sorgo (Sorghum bicolor (L.) Moench). O farelo de soja e a mistura de ureia com sulfato de amônio foram adicionados para que as dietas tivessem um teor mínimo de 7\% de proteína bruta. A composição química dos ingredientes das dietas experimentais está apresentada na Tabela 1.

As dietas compuseram: dieta I - 95\% de cana-de-açúcar, $4 \%$ de farelo de soja e 1\% de ureia; dieta II- 95\% de silagem de capim-elefante, $4,1 \%$ de farelo de soja e 0,9\% de ureia: sulfato de amônio (9:1); dieta III -95\% de silagem de milho, 4,8\% de farelo de soja e 0,2 \% de ureia:sulfato de amônio (9:1); dieta IV - 95\% de silagem de sorgo, 4,8\% de farelo de soja e 0,2\% de ureia:sulfato de amônio (9:1), respectivamente.

As dietas experimentais foram fornecidas uma vez ao dia, às 6 h. A mistura de uréia:sulfato de amônio foi diluída em água na proporção de 1:4 e distribuída uniformemente sobre o alimento volumoso no cocho, sendo adicionado, em seguida, o farelo de soja. O período experimental teve duração de 15 dias, sendo 10 de adaptação às dietas e cinco dias de coleta total de fezes.

Diariamente as sobras foram pesadas para determinar o consumo de alimentos pelos animais; foram feitos ajustes para que as sobras representassem entre 5 e $10 \%$ do total ofertado. Durante o período de colheita foram amostrados alimentos e sobras, que foram em seguida congelados para análises futuras. 
Tabela 1. Composição química da cana-de-açúcar, das silagens de capim-elefante, de milho e de sorgo, do farelo de soja e da uréia

\begin{tabular}{lcccccc}
\hline & \multicolumn{5}{c}{ Alimentos } \\
\cline { 2 - 7 } Itens $^{1}$ & Cana-de-açúcar & $\begin{array}{c}\text { Silagem de } \\
\text { capim-elefante }\end{array}$ & $\begin{array}{c}\text { Silagem de } \\
\text { milho }\end{array}$ & $\begin{array}{c}\text { Silagem de } \\
\text { sorgo }\end{array}$ & $\begin{array}{c}\text { Farelo de } \\
\text { soja }\end{array}$ & Uréia/SA \\
\hline MS (\%) & 25,77 & 23,23 & 34,84 & 24,59 & 87,09 & 98,99 \\
MO $^{2}$ & 98,25 & 94,18 & 94,29 & 93,18 & 94,03 & 99,83 \\
PB $^{2}$ & 2,79 & 6,26 & 7,06 & 4,93 & 48,82 & 253,67 \\
NIDN $^{3}$ & 16,16 & 12,04 & 13,52 & 22,22 & 1,55 & - \\
NIDA $^{3}$ & 3,30 & 9,89 & 6,02 & 8,80 & 0,90 & - \\
EE $^{2}$ & 1,06 & 2,30 & 2,57 & 2,18 & 1,04 & - \\
$\mathrm{CT}^{2}$ & 94,40 & 85,62 & 84,66 & 86,08 & 44,18 & - \\
FDN $^{2}$ & 48,87 & 74,23 & 57,12 & 60,41 & 13,30 & - \\
FDNcp $^{2}$ & 47,70 & 64,55 & 54,75 & 58,76 & 11,60 & - \\
$\mathrm{CNF}^{2}$ & 46,70 & 21,07 & 29,90 & 27,32 & 32,57 & - \\
FDA $^{2}$ & 23,67 & 45,39 & 26,72 & 32,18 & 6,88 & - \\
Lignina $^{2}$ & 4,85 & 8,61 & 5,17 & 5,40 & 1,99 & - \\
\hline
\end{tabular}

1'MS - Matéria Seca, \%; MO - matéria orgânica; PB - proteína bruta; NIDN - compostos nitrogenados insolúveis em detergente neutro; NIDA - compostos nitrogenados insolúveis em detergente ácido; EE - extrato etéreo; FDN - fibra em detergente neutro; FDNcp - fibra em detergente neutro corrigida para cinzas e proteínas; CNF - carboidratos não-fibrosos, FDA - fibra em detergente ácido; ${ }^{2}$ valores expressos em \% da matéria seca, ${ }^{3}$ valores expressos em $\%$ do $\mathrm{N}$ total.

A digestibilidade aparente total dos nutrientes foi calculada segundo os métodos descritos por Schneider \& Flatt (1975). As coletas de fezes foram realizadas em sacolas adaptadas aos animais. A cada 12 horas, durante os cinco dias de coleta de fezes, elas foram retiradas das sacolas, sendo imediatamente homogeneizadas, pesadas, amostradas (5\%) e congeladas a $-10^{\circ} \mathrm{C}$, para análises posteriores.

As amostras de alimentos, sobras e fezes foram descongeladas à temperatura ambiente, pré-secas em estufa de ventilação forçada a $55{ }^{\circ} \mathrm{C}$ por 72 horas. Foram determinados os teores de matéria seca (MS), compostos nitrogenados totais (NT), extrato etéreo (EE), matéria mineral (MM), fibra em detergente neutro (FDN), fibra em detergentes ácido (FDA), lignina (LIG) e compostos nitrogenados insolúveis em detergente ácido e neutro (NIDA e NIDN, respectivamente), segundo métodos descritos por Silva \& Queiroz (2002). Os carboidratos nãofibrosos (CNF) foram calculados pela equação proposta pelo NRC (2001), em que: $C N F=100-(\% F D N c p+\% P B$ $+\% E E+\%$ Cinzas). Os dados de consumo e digestibilidade aparente total dos nutrientes foram submetidos à análise de variância, e as médias comparadas pelo teste de Student-Newman-Keuls, utilizando-se o Sistema de Análises Estatísticas e Genéticas - SAEG (Universidade Federal de Viçosa, 2000). Os valores de NDT observados foram calculados pela equação: $N D T=P B D+2,25 E E D$ + FDNcpD + CNFD, enquanto os de NDT estimados para mantença de cada alimento foram obtidos pela equação do NRC (2001): $N D T m=(P B D+2,25 A G D+F D N p D$ + CNFD) -7.

Os valores de proteína bruta digestível (PBD), fibra em detergente neutro digestível corrigida para proteína
(FDNpD) e carboidratos não fibrosos digestíveis (CNFD) foram estimados segundo as equações descritas por Weiss et al. (1992): $P B D$ (para alimentos volumosos) $=$ $P B \times \operatorname{Exp}(-1,2 \times(P I D A / P B) ; ~ e ~ P B D$ (para alimentos concentrados $)=P B \times[1-(0,4 \times P I D A / P B)]$; em que: $P I D A=$ proteína insolúvel em detergente ácido; $F D N p D=0,75$ $(F D N p-L) \times\left[1-(L / F D N p)^{0,667}\right]$; em que $\mathrm{L}=$ Lignina, $C N F D=0,98 \times C N F \times P A F$; em que PAF $=$ fator de ajuste para processamento físico, de acordo com os valores de PAF propostos pelo NRC (2001), sendo utilizados 0,94 para silagem de milho e 1,00 para os demais alimentos, respectivamente. O teor de ácido graxo digestível (AGD) foi estimado segundo a equação proposta por Allen (2000): $A G D=E E-1$.

A digestibilidade verdadeira da $\mathrm{PB}$, do $\mathrm{EE}$ e do $\mathrm{CNF}$ foi corrigida para excreção fecal metabólica para cada nutriente, subtraindo-se dos valores obtidos pelas equações de PBD, EED e CNFD: 2,7; 1,4 e 3,1 unidades, respectivamente (Weiss etal., 1992).

A comparação dos valores observados e estimados para o NDT e as frações digestíveis de PB, FDN, CNF e EE foi feita pelo procedimento de validação das equações por intermédio do ajuste do modelo de regressão linear simples dos valores preditos sobre os observados:

$$
\widehat{Y}_{i}=\beta_{0}+\beta_{1} X_{i}+e_{i}
$$

Em que: $\widehat{Y}_{i}=$ valor observado;

$\beta_{0}=$ constante da equação;

$\beta_{1}=$ coeficiente angular da reta;

$X_{\mathrm{i}}=$ valor predito; $\mathrm{e}$

$e_{\mathrm{i}}=$ erro aleatório associado a cada observação. 
As estimativas dos parâmetros de regressão foram testadas sobre as hipóteses:
(1) $\mathrm{H}_{0}: \beta_{0}=0$
На : $\beta_{0} \neq 0$
(2) $\mathrm{H}_{0}: \beta_{1}=1$
На : $\beta_{1} \neq 1$

No caso de não-rejeição de ambas as hipóteses de nulidade, concluiu-se que os valores preditos e observados são similares. Para todos os procedimentos estatísticos foi adotado um nível de significância de 0,05.

\section{RESULTADOS E DISCUSSÃO}

Os consumos médios dos nutrientes e seus respectivos coeficientes de variação estão apresentados na Tabela 2. Observou-se que os animais alimentados com as silagens de capim-elefante, de milho e de sorgo consumiram maior quantidade $(\mathrm{P}<0,05)$ de $\mathrm{MS}, \mathrm{PB}$, EE e FDNcp do que aqueles alimentados com cana-de-açúcar. Magalhães et al. (2004) e Mendonça et al. (2004) observaram consumos de MS 16,1 e 21,2\%, respectivamente, superiores para dietas à base de silagem de milho quando comparadas com dietas que continham cana-de-açúcar como volumoso exclusivo para vacas leiteiras.

Os animais que receberam silagens de capim-elefante, milho e sorgo apresentaram consumos semelhantes ( $\mathrm{P}>$ 0,05) de MO. Contudo, o consumo de MO (g/dia) nos animais alimentados com silagem de milho foi superior ( $\mathrm{P}$ $<0,05)$ ao daqueles alimentados com cana-de-açúcar. O baixo consumo de FDN pelos ovinos alimentados com cana-de-açúcar ocorreu devido ao baixo consumo de MS e ao menor teor de FDN nesse alimento, resultado esse semelhante ao relatado por Rocha Jr. (2002). A cana-deaçúcar utilizada no presente estudo apresentou valor médio de FDN inferior ao descrito por Valadares Filho et al. (2002), 55,87\%.

Os animais alimentados com silagem de milho apresentaram maiores consumos de CNF $(\mathrm{P}<0,05)$ do que os alimentados com silagem de capim-elefante (Tabela 3). Tal fato pode ser explicado pelos menores teores de CNF encontrados na silagem de capim-elefante (24,48\%), uma vez que o consumo de matéria seca foi semelhante entre essas dietas.

Para o consumo de NDT, não houve diferença (P > $0,05)$ entre as silagens de capim-elefante e sorgo e a canade-açúcar (Tabela 3). Todavia, o consumo de NDT pelos animais alimentados com silagem de milho foi maior $(\mathrm{P}<$ $0,05)$ do que o consumo médio para os ovinos alimentados com cana-de-açúcar.

Os consumos de MS expressos em percentagem do peso vivo, que variaram de 2,05 (silagem de capim-elefante) a 2,33 (silagem de milho), não diferiram $(P>0,05)$ entre as silagens. Da mesma forma, os de FDN também não diferiram $(\mathrm{P}>0,05)$ entre as mesmas, apresentando os valores de 1,$26 ; 1,21$; e 1,27\% do peso vivo para as silagens de capim-elefante, de milho e de sorgo, respectivamente.

Os maiores consumos obtidos com as dietas à base de silagens provavelmente tenham ocorrido em razão da maior taxa de digestão da fração de FDN nessas dietas (Tabela 3). Segundo Van Soest (1965), o consumo voluntário de matéria seca é altamente relacionado ao conteúdo de FDN

Tabela 2. Consumo médio diário de nutrientes para as dietas à base de cana-de-açúcar e silagens de capim-elefante, milho e sorgo e respectivos coeficientes de variação

\begin{tabular}{lccccc}
\hline & \multicolumn{5}{c}{ Dietas $^{\mathbf{1}}$} \\
\cline { 2 - 6 } Itens $^{2}$ & Cana-de-açúcar & $\begin{array}{c}\text { Silagem de } \\
\text { capim-elefante }\end{array}$ & $\begin{array}{c}\text { Silagem de } \\
\text { milho }\end{array}$ & $\begin{array}{c}\text { Silagem de } \\
\text { sorgo }\end{array}$ & CV (\%) \\
\cline { 2 - 7 } MS & & & Consumos (g/dia) $^{\mathbf{3}}$ & & \\
MO & $726,33 \mathrm{~b}$ & $990,21 \mathrm{a}$ & $1212,16 \mathrm{a}$ & 18,32 \\
PB & $709,46 \mathrm{~b}$ & $926,61 \mathrm{ab}$ & $1140,39 \mathrm{a}$ & $981,78 \mathrm{ab}$ & 18,28 \\
EE & $59,27 \mathrm{c}$ & $111,93 \mathrm{a}$ & $124,53 \mathrm{a}$ & $88,19 \mathrm{~b}$ & 17,33 \\
CT & $7,06 \mathrm{c}$ & $23,05 \mathrm{~b}$ & $30,77 \mathrm{a}$ & $22,55 \mathrm{~b}$ & 16,05 \\
FDNcp & $660,94 \mathrm{~b}$ & $824,07 \mathrm{ab}$ & $991,66 \mathrm{a}$ & $877,81 \mathrm{ab}$ & 18,95 \\
CNF & $336,43 \mathrm{~b}$ & $608,05 \mathrm{a}$ & $630,61 \mathrm{a}$ & $587,72 \mathrm{a}$ & 16,94 \\
NDT & $324,49 \mathrm{ab}$ & $215,95 \mathrm{~b}$ & $361,24 \mathrm{a}$ & $290,05 \mathrm{ab}$ & 23,28 \\
& $441,46 \mathrm{~b}$ & $601,45 \mathrm{ab}$ & $753,86 \mathrm{a}$ & $638,45 \mathrm{ab}$ & 20,35 \\
MS & & & & $2,27 \mathrm{a}$ & 15,22 \\
MO & $1,59 \mathrm{~b}$ & $2,05 \mathrm{a}$ & $2,33 \mathrm{a}$ & $2,12 \mathrm{a}$ & 16,94 \\
FDNcp & $1,56 \mathrm{~b}$ & $1,92 \mathrm{ab}$ & $2,19 \mathrm{a}$ & $1,27 \mathrm{a}$ & 15,55 \\
\hline
\end{tabular}

${ }^{1}$ Valores seguidos por letras diferentes, na mesma linha, diferem significativamente $(\mathrm{P}<0,05)$, pelo teste de Student-Newman-Keuls; ${ }^{2} \mathrm{MS}$ - matéria seca; MO - matéria orgânica; PB - proteína bruta; EE - extrato etéreo; FDNcp - fibra em detergente neutro corrigida para cinzas e proteínas; CNF - carboidratos não-fibrosos; NDT- nutrientes digestíveis totais. ${ }^{3} \mathrm{~g} / \mathrm{dia}$ - gramas por dia; ${ }^{4} \% \mathrm{PV}$ percentagem do peso vivo. 
do alimento e da dieta, visto que a fermentação e a taxa de passagem da fração fibrosa pelo rúmen-retículo são mais lentos que outros constituintes dietéticos. Não obstante, o baixo consumo de dietas contendo cana-de-açúcar está relacionado à baixa digestibilidade da FDN (Oliveira et al., 2001), à baixa taxa de passagem e ao elevado tempo de retenção desse alimento (Preston \& Leng, 1978; Preston, 1982; Magalhães et al., 2004).

Na Tabela 3 estão apresentadas as médias observadas para as digestibilidades aparentes dos nutrientes e seus respectivos coeficientes de variação. Foi observado que as digestibilidades aparentes da MS, MO, PB e EE não diferiram entre as dietas $(\mathrm{P}>0,05)$. Para a digestibilidade da FDNcp, observaram-se maiores valores para as silagens de milho e de sorgo, que, por sua vez, não diferiram entre si. As maiores digestibilidades obtidas para a FDNcp nas silagens de milho e de sorgo ocorreram, possivelmente, em virtude do menor valor de FDN indigestível delas (Campos et al., 2006).

Para o coeficiente de digestibilidade aparente dos CNF, observou-se que não houve diferença $(P>0,05)$ entre as silagens de milho e sorgo, e entre a de capim-elefante e a cana-de-açúcar.

Rocha Jr. et al. (2003a) obtiveram coeficientes de digestibilidade de FDN e CNF para a cana-de-açúcar de 18,43 e $96,38 \%$, respectivamente. Para a silagem de milho foram observados coeficientes de digestibilidade dos nutrientes semelhantes aos citados por Rocha Jr. et al. (2003a), exceto para FDN e CNF, que foram de 34,15 e $88,88 \%$, respectivamente.

Souza et al. (2003) avaliaram os coeficientes de digestibilidade aparente dos nutrientes de silagens de diferentes híbridos de sorgo e observaram resultados semelhantes aos obtidos neste trabalho, com exceção do valor do coeficiente de digestibilidade da PB (49,3\%).

Os coeficientes de digestibiliade dos nutrientes do sorgo apresentaram valores semelhantes aos da silagem de milho, tais características nutricionais justificam a semelhança entre as silagens de milho e sorgo.

Em relação ao coeficiente de digestibilidade aparente dos CNF, observou-se que não houve diferença significativa $(\mathrm{P}>0,05)$ entre as silagens de milho e sorgo e entre a silagem de capim-elefante e a cana-de-açúcar.

Na Tabela 4 estão apresentados os valores médios de NDT e das frações digestíveis da PB, FDNp, EE e CNF, estimados pelas equações propostas pelo NRC (2001), e os valores determinados experimentalmente com ovinos para os diferentes alimentos volumosos. Na Tabela 5 estão representadas as médias gerais e suas respectivas estimativas dos coeficientes da regressão.

Vale ressaltar que os valores de NDT determinados neste estudo foram obtidos por meio de ensaios com ovinos alimentados à vontade, ao passo que os valores de NDT gerados pelas equações NRC (2001) são estimados para mantença. Por essa razão, os valores estimados de NDT superiores a $60 \%$ foram multiplicados pelo fator de correção 0,95, uma vez que Valadares Filho et al. (2003) constataram que o valor de NDT das dietas com animais alimentados à vontade corresponde a 95\% do valor obtido próximo à mantença.

Observa-se que houve diferença $(\mathrm{P}<0,05)$ entre os valores de NDT estimados e observados para o conjunto de volumosos avaliados, representada pela rejeição das duas hipóteses de nulidade $\left(H_{0}: \beta_{0}=0 ; \beta_{1}=1\right)$. A Figura 1 mostra a dispersão dos valores estimados e observados em torno da reta que expressa a relação " $Y=X$ ".

As estimativas dos coeficientes $\beta_{0}$ e $\beta_{1}$ das equações de regressão diferiram de 0 e $1(\mathrm{P}<0,05)$ entre os valores estimados e observados das frações da PBD e dos CNFD. Os valores de PBD foram drasticamente subestimados pela equação do NRC (2001). Os de CNFD foram superestimados pelas equações do NRC (2001). As Figuras 2 e 3 ilustram a dispersão dos pontos em torno da reta $(\mathrm{Y}=\mathrm{X})$.

Tabela 3. Médias dos coeficientes de digestibilidades aparentes dos nutrientes (\%) e respectivos coeficientes de variação para as dietas à base de cana-de-açúcar e silagens de capim-elefante, milho e sorgo

\begin{tabular}{|c|c|c|c|c|c|}
\hline \multirow[b]{2}{*}{ Itens $^{2}$} & \multirow[b]{2}{*}{ Cana-de-açúcar } & \multicolumn{3}{|c|}{ Dietas $^{1}$} & \multirow[b]{2}{*}{ CV (\%) } \\
\hline & & $\begin{array}{c}\text { Silagem de } \\
\text { capim-elefante }\end{array}$ & $\begin{array}{l}\text { Silagem de } \\
\text { milho }\end{array}$ & $\begin{array}{l}\text { Silagem de } \\
\text { sorgo }\end{array}$ & \\
\hline MS & 54,69 a & $55,35 \mathrm{a}$ & $60,60 \mathrm{a}$ & $59,55 \mathrm{a}$ & 5,8 \\
\hline MO & 59,85 a & 59,36 a & 64,57 a & 62,41 a & 5,5 \\
\hline PB & 80,16 a & 91,66 a & 89,87 a & 87,62 a & 9,4 \\
\hline $\mathrm{EE}$ & 45,56 a & 69,26 a & 80,51 a & 65,62 a & 18,0 \\
\hline $\mathrm{CT}$ & 58,76 a & 57,46 a & 60,57 a & 60,12 a & 5,4 \\
\hline FDNcp & 38,78 c & $49,65 \mathrm{~b}$ & 57,97 a & 56,79 a & 6,4 \\
\hline CNF & 75,97 a & 72,07 a & $55,05 \mathrm{~b}$ & $56,88 \mathrm{~b}$ & 8,2 \\
\hline
\end{tabular}

${ }^{1}$ Valores seguidos por letras diferentes, na mesma linha, diferem significativamente $(\mathrm{P}<0,05)$, pelo teste de Student-Newman-Keuls; ${ }^{2} \mathrm{MS}$

- matéria seca; MO - matéria orgânica; PB - proteína bruta; EE - extrato etéreo; FDNcp - fibra em detergente neutro corrigida para cinzas e proteínas; CNF - carboidratos não-fibrosos. 
Tabela 4. Médias dos valores de NDT e das frações digestíveis da proteína bruta (PBD), da fibra em detergente neutro (FDND), do extrato etéreo (EED) e carboidratos não-fibrosos (CNFD) estimados pela equação proposta pelo NRC (2001) e observados no ensaio com ovinos

\begin{tabular}{lcccccccccc}
\hline Alimento & NDT $^{\mathbf{1}}$ & $\mathbf{N D T}^{\mathbf{2}}$ & PBD $^{1}$ & $\mathbf{P B D}^{2}$ & FDND $^{1}$ & FDND $^{2}$ & EED $^{1}$ & EED $^{2}$ & CNFD $^{\mathbf{1}}$ & CNFD $^{\mathbf{2}}$ \\
\hline Cana-de-açúcar & 63,84 & 60,34 & 2,17 & 5,72 & 24,02 & 16,48 & $-1,34$ & 0,53 & 44,76 & 36,95 \\
Silagem de capim-efefante & 57,00 & 60,57 & 2,98 & 9,38 & 34,34 & 34,13 & $-0,1$ & 1,55 & 20,66 & 18,58 \\
Silagem de milho & 57,53 & 63,16 & 4,49 & 8,59 & 27,01 & 27,28 & 0,17 & 2,33 & 29,41 & 21,9 \\
Silagem de sorgo & 57,94 & 59,91 & 4,45 & 6,60 & 28,31 & 26,99 & 1,18 & 1,40 & 29,49 & 21,44 \\
\hline
\end{tabular}

1Valores estimados pelas equações do NRC (2001), ${ }^{2}$ Valores observados no ensaio com ovinos.

Tabela 5. Médias e estimativas dos coeficientes de regressão dos valores de NDT e das frações digestíveis dos nutrientes, estimados pela equação proposta pelo NRC (2001) e observados no experimento com ovinos

\begin{tabular}{|c|c|c|c|c|c|c|}
\hline \multicolumn{3}{|c|}{ Descrição das Relações } & \multicolumn{4}{|c|}{ Regressão Linear ${ }^{2}$} \\
\hline \multirow{2}{*}{ Variável $^{1}$} & \multirow{2}{*}{$\begin{array}{c}\text { Valores } \\
\text { estimados (\%) }\end{array}$} & \multirow{2}{*}{$\begin{array}{c}\text { Valores } \\
\text { observados (\%) }\end{array}$} & \multicolumn{2}{|c|}{ Intercepto } & \multicolumn{2}{|c|}{ Coeficiente de Inclinação } \\
\hline & & & Estimativa & Valor-P ${ }^{3}$ & Estimativa & Valor-P $\mathbf{P}^{4}$ \\
\hline NDT & 59,08 & 61,00 & 63,3700 & 0,0001 & $-1,7170$ & 0,0007 \\
\hline PBD & 3,52 & 7,57 & 1,4350 & 0,0001 & 0,8350 & 0,0001 \\
\hline FDND & 28,42 & 26,22 & 27,0350 & 0,0001 & 0,5540 & 0,4871 \\
\hline EED & $-0,27$ & 1,45 & 0,1200 & 0,6175 & 0,3630 & 0,0005 \\
\hline CNFD & 31,08 & 30,90 & 43,4450 & 0,0001 & $-3,7060$ & 0,0332 \\
\hline
\end{tabular}

${ }^{1}$ NDT - Nutrientes digestíveis totais, PBD - proteína bruta digestível, FDND - fibra em detergente neutro digestível, EED - Extrato etéreo digestível, CNFD - carboidratos não-fibrosos digestíveis; ${ }^{2} \widehat{Y}_{i}=\widehat{\beta}_{0}+\widehat{\beta}_{1} \mathrm{X}_{i} ;{ }^{3} H_{0}: \beta_{0}=0 ;{ }^{4} H_{0}: \beta_{1}=1$.

Inferiu-se, para a fração digestível da FDN, que não há correspondência entre os valores observados e estimados, uma vez que houve rejeição $(\mathrm{P}<0,05)$ da hipótese 1 e não-rejeição da hipótese 2 ( $P>0,05)$. Na Figura 4, pode-se observar os valores de FDND estimados e observados e a distribuição dos pontos em torno da reta ideal $(\mathrm{Y}=\mathrm{X})$ para os diferentes alimentos. A fração digestível da FDN não foi adequadamente estimada pela equação proposta no NRC (2001). Rocha Júnior et al. (2003b) constataram que a fração digestível da FDN foi subestimada

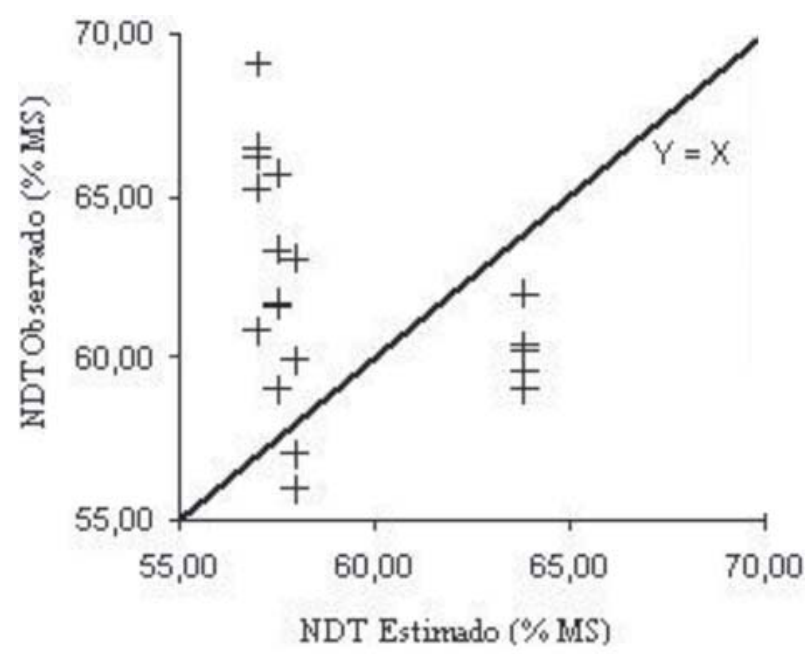

Figura 1. Relação entre os valores de NDT observados e estimados pelas equações do NRC (2001) para os diferentes volumosos. para alimentos volumosos tropicais. A falta de ajuste da referida equação ocorre, possivelmente, devido a características particulares da fração não-digerível da fibra em detergente neutro das gramíneas tropicais.

Costa (2002) não encontrou diferenças $(\mathrm{P}>0,05)$ entre os valores de NDT estimados e observados ao avaliar um conjunto de alimentos volumosos e concentrados, mas observou que as frações digestíveis da FDN e da PB foram superestimadas pelas equações do NRC (2001) em 16,08 e 16,12\%, respectivamente.

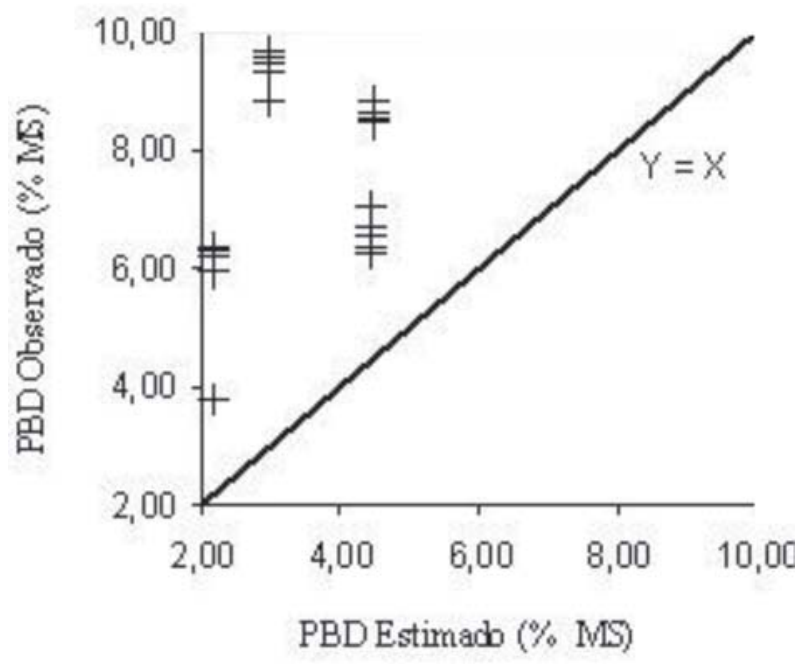

Figura 2. Relação entre os valores da fração digestível da PB (PBD) observados e estimados pelas equações do NRC (2001) para os diferentes volumosos. 


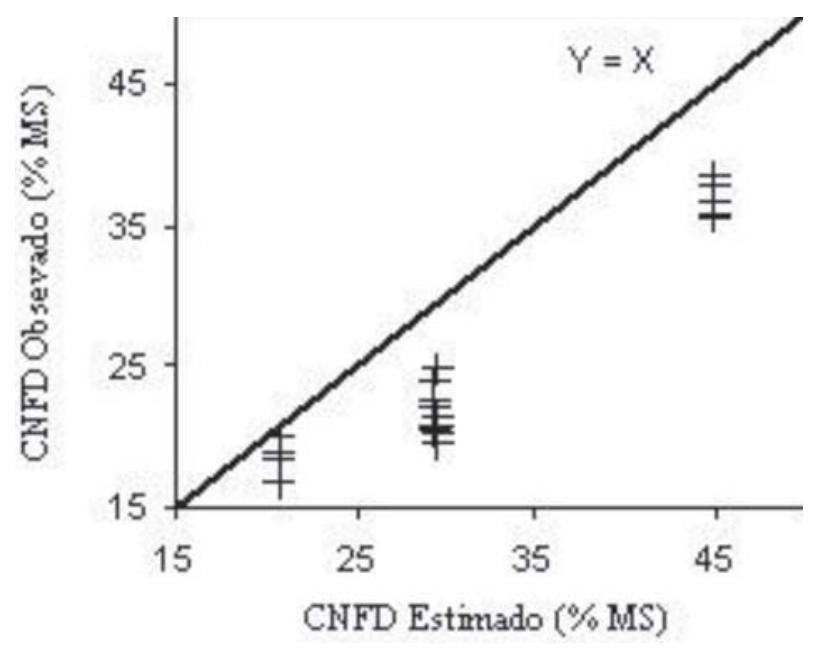

Figura 3. Relação entre os valores da fração digestível do CNF (CNFD) observados e estimados pelas equações do NRC (2001) para os diferentes volumosos.

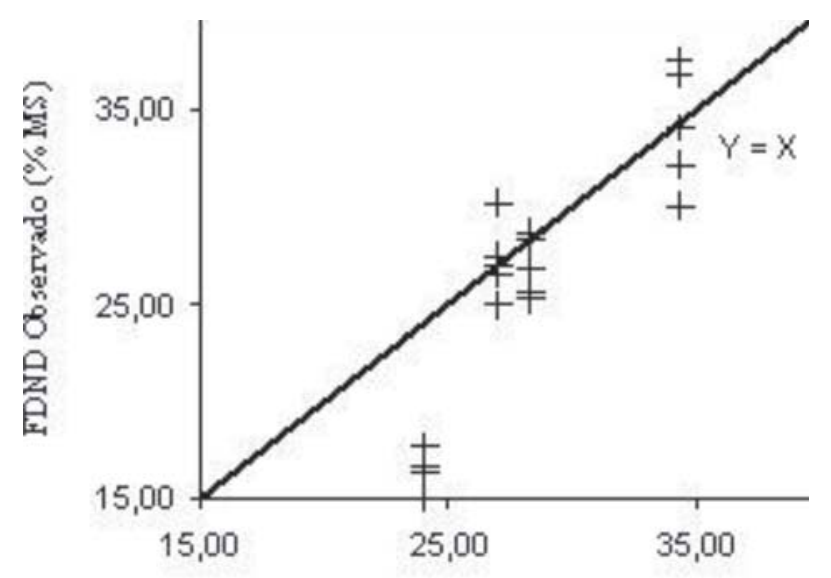

FDND Estimado ( $\%$ MS)

Figura 4. Relação entre os valores da fração digestível da FDN (FDND) observados e estimados pelas equações do NRC (2001) para os diferentes volumosos.

A estimativa da fração digestível do EE apresentou valores baixos, e até mesmo negativos, devido aos baixos teores de EE na composição química das forragens avaliadas (Tabela 1), aliado ao fator de correção para as perdas de energia fecal metabólicas, que, possivelmente, para as gramíneas tropicais trata-se de um valor superestimado (Tabela 5). Para essa fração observou-se a não-rejeição da primeira hipótese de nulidade $\left(H_{0}: \beta_{0}=0\right)$, mas rejeição da segunda $\left(H_{0}: \beta_{1}=1\right)$. A Figura 5 ilustra a dispersão dos valores de EED estimados e observados em torno da reta ideal $(\mathrm{Y}=\mathrm{X})$, e mostra que tal fração foi subestimada pela equação do NRC (2001).

Silva (2004) também encontrou diferença entre os valores de NDT estimados e observados ao estudar o capim-elefante em diferentes idades de rebrota, concluindo que as frações FDND, EED e PBD foram subestimadas pelas equações do NRC (2001).

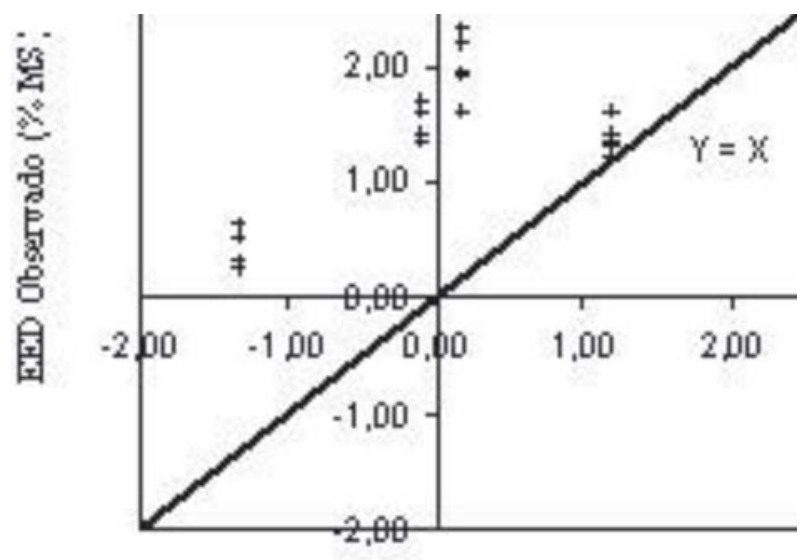

EDD Estim ado (\% MS)

Figura 5. Relação entre os valores da fração digestível do EE (EED) observados e estimados pelas equações do NRC (2001) para os diferentes volumosos.

\section{CONCLUSÕES}

Os maiores consumos de nutrientes obtidos com as dietas à base de silagens, provavelmente, tenham ocorrido em razão da maior digestibilidade da fração de FDN das mesmas.

Os valores de NDT e das frações digestíveis estimados a partir das equações propostas pelo NRC (2001) mostraram-se inadequados para estimar o valor energético das gramíneas tropicais avaliadas neste estudo.

\section{REFERÊNCIAS}

Allen MS (2000) Effects of diet on short-term regulation of feed intake by lactating dairy cattle. Journal of Dairy Science, 83:1598-1624.

Campos PRSS, Valadares Filho SC \& Cecon PR (2006). Estudo comparativo da cinética de degradação ruminal de forragens tropicais em bovinos e ovinos. Arquivo Brasileiro de Medicina Veterinária e Zootecnia, 58:1181-1191.

Cappelle ER, Valadares Filho SC \& Coelho da Silva JF (2001) Estimativas do valor energético a partir das características químicas e bromatológicas dos alimentos. Revista Brasileira de Zootecnia, 30:1837-1856.

Costa MAL (2002) Desempenho de novilhos zebuínos e validação das equações do NRC (2001) para predizer o valor energético dos alimentos nas condições brasileiras. Dissertação de mestrado. Universidade Federal de Viçosa, Viçosa. 81p.

Magalhães ALR, Campos JMS \& Valadares Filho SC (2004) Canade-açúcar em substituição à silagem de milho em dietas para vacas em lactação: desempenho e viabilidade econômica. Revista Brasileira de Zootecnia, 33:1292-1302.

Mendonça SS, Campos JMS \& Valadares Filho SC (2004) Consumo, digestibilidade aparente, produção e composição do leite e variáveis ruminais em vacas leiteiras alimentadas com dietas à base de cana-de-açúcar. Revista Brasileira de Zootecnia, 33:481-492.

National Research Council - NRC (2001) Nutrient requirements of dairy cattle. $7^{\text {a }}$ ed. Washington, National Academic Press. 381p.

Rev. Ceres, Viçosa, v. 57, n.1, p. 079-086, jan/fev, 2010 
Oliveira MDS, Casagrande AA \& Oliveira EFS (2001) Efeito da digestibilidade in vitro de variedades de cana-de-açúcar sobre seu valor como alimento para bovinos. ARS Veterinária, 17:238243.

Preston TR \& Leng RA (1978) La caña de azúcar como alimento para los bovinos. Revista Mundial de Zootecnia, 27:7-12.

Preston TR (1982) Nutritional limitations associated with the feeding of tropical forages. Journal of Animal Science, 54:877883.

Robinson PH, Givens DI \& Getachew G (2004) Evaluation of NRC, UC Davis and ADAS approaches to estimate the metabolizable energy values of feeds at maintenance energy intake from equations utilizing chemical assays and in vitro determinations. Animal Feed Science and Technology, 114:7590 .

Rocha Júnior VR (2002) Tabelas brasileiras de composição de alimentos, determinação e estimação do valor energético dos alimentos para ruminantes. Tese de doutorado. Universidade Federal de Viçosa, Viçosa. 252p.

Rocha Júnior VR, Valadares Filho SC \& Borges AM (2003a) Determinação do valor energético de alimentos para ruminantes pelo sistema de equações. Revista Brasileira de Zootecnia, 32:473-479.

Rocha Júnior VR, Valadares Filho SC \& Magalhães KA (2003b) Estimativa do valor energético dos alimentos e validação das equações propostas pelo NRC (2001). Revista Brasileira de Zootecnia, 32:480-490.

Schneider BH \& Flatt WP (1975) The evaluation of feeds through digestibility experiments. Georgia, The University of Georgia Press. 423p.
Silva DJ \& Queiroz AC (2002) Análise de alimentos - Métodos químicos e biológicos, 3 ed. Viçosa, UFV: Imprensa Universitária. 235p.

Silva PA (2004) Valor energético do capim-elefante (Penisetum purpureum, Schum) em diferentes idades de rebrota e determinação da digestibilidade "in vivo" da fibra em detergente neutro. Dissertação de mestrado. Universidade Federal de Viçosa, Viçosa. 57p.

Souza VG, Pereira OG \& Garcia R (2003) Valor nutritivo de silagens de sorgo. Revista Brasileira de Zootecnia, 32:753-759.

SAEG (2000) Sistema de análises estatísticas e genéticas, Manual do usuário (versão 8.0). Viçosa, Universidade Federal de Viçosa. 301p.

Valadares Filho SC, Rocha Júnior VR \& Cappelle ER (2002) Tabelas Brasileiras de Composição de Alimentos para Bovinos. $1^{\mathrm{a}}$ ed. Viçosa, DZO-DPI-UFV. 297p.

Valadares Filho SC, Silva PA \& Rocha Júnior VR (2003) Estimativa do valor energético em condições tropicais. In: Simpósio sobre Volumosos na Produção de Ruminantes: Valor Alimentício de Forragens, Jaboticabal. Anais, Jaboticabal/Editora Funep. p.71-86.

Van Soest PJ (1965) Symposium on factors influencing the voluntary intake in relation to chemical composition and digestibility. Journal of Animal Science, 24:834-843.

Weiss WP (1993) Predicting energy values of feed. Journal of Dairy Science, 76:1802-1811.

Weiss WP, Conrad HR \& Pierre NRS (1992) A theoretically-based model for predicting total digestible nutrient values of forages and concentrates. Animal Feed Science and Technology, 39:95110 . 